\title{
Design and Implementation of Electronic Network System of Taxation based on the Internet and Big Data Perspective
}

\author{
Chen Peng \\ Pingxiang University, \\ Pingxiang,Jiangxi,337000 China
}

\begin{abstract}
In this paper, we conduct theoretical design and implementation of electronic network system of taxation base on the internet and big data perspective. On the Internet, through the information system realizes the tax department and relevant government departments and the information communication and exchange between taxpayers and achieves information resource sharing. Therefore, combining information technique with tax system is necessary and feasible. In the following sections, we demonstrate the proposed method in detail with simulation and analysis.
\end{abstract}

Keywords: Electronic Taxation; Internet and Big Data; System Development; Interface Design.

\section{Introduction}

With the advent of the era of big data, the tax authorities for many years and has accumulated rich and valuable data resources, how to acquire from the vast and complex data set and build feasible tax data model, to provide decision support for management departments at all different levels has become the important research content of tax information application. With the explosion of big data, bad data followed, lead to poor data quality, data availability is greatly reduced. To ensure data availability is related to the national economy and people's livelihood of the era of large data, fiscal and tax, resource allocation and other aspects of a major strategic task, is to analyze big data era electronic tax data and use the premise of guarantee. The features of the usability of data could be separated into the following perspectives. Data collection contains enough data to answer queries and support various calculations. After the taxpayer to handle the tax registration, to register at the same time to complete the information in each module, otherwise the subsequent management will be a problem. To the logical relationship between the associated data, collection between each module in the system has the internal logic relations, such as the property tax, land tax and property tax must first registration, tax registration, after finally to make declaration, tax, statistics, order cannot be reversed, or illogical would be unable to operate. Each data in the data set can be accurately represents entities in the real world. Taxpayers' tax registration information change which needs to amend the corresponding relevant data collection system, statistical query error will occur when otherwise [1].

Using the network technology of implementing taxation, improve tax collection and administration and service level, is not only the scientific and technological progress and the inevitable trend of social development, is also the realistic need, which the tax authority institution reform and function change. Electronic tax is an important content of e-government. Said simply, it refers to the tax authorities to use network as the core of the information technology to realize part of tax collection management and taxation service functions. Its specific form performance for tax authorities is to use of the Internet technology to build the related virtual online tax service agencies and partly instead of the traditional tax agency. Provide tax matters management and services to 
the public. Electronic tax is an important part of tax information of tax information senior forms [2]. Successful implementation of the electronic tax should be with good tax information infrastructure and talent support [3].

On the Internet, through the information system realizes the tax department, and relevant government departments and the information communication and exchange between taxpayers and achieve information resource sharing, the purpose of the business activity coordination operation. Breakthrough the limitation of time and space, can let the taxpayer anytime and anywhere through the computer directly to the tax authorities, tax, tax authorities and can through the web site for the corresponding service, saves tax cost, and can deal with tax-related affairs easily and quickly, makes the tax collection and tax work from the traditional manual, paper to electronic, paperless operation, by the novel electronic bills instead of traditional paper physical paper, electronic tax records can ensure tax file integrity and efficiency.

To modify and enhance the current system, we conduct theoretical design and implementation of electronic network system of taxation base on the internet and big data perspective. They are both important in the electronic tax information system of tax data, and various tax publicity information. There is a mix of tax departments at all levels of staff and external customers, users in the system is also constantly adjust the change in order to realize the different data information for different users have different access rights. A lot of the information in the electronic tax information system category and different categories of information required by the security level is not the always same. Some information permissions may control to a specific user. Some information for the users has no control of the whole system. So the requirement of information control granularity is different. The complexity of the permissions granted and access the relationship between the particle sizes is the higher the complexity of the permissions granted. Get the granularity of access. In the figure one, we show the general structure of the traditional electronic tax system.

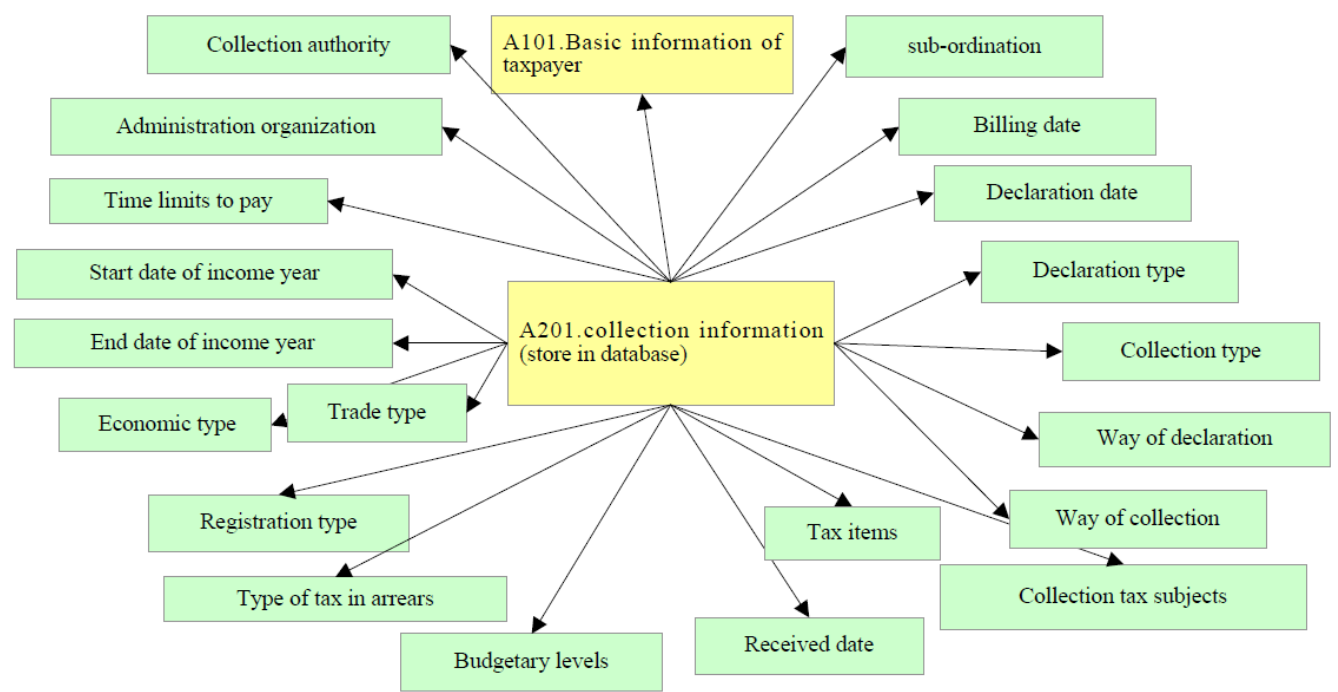

Fig. 1The General Structure of the Traditional Electronic Tax System

\section{The Implementation of the System}

The Big Data Concepts and Application. Predecessor of the concept of big data is a huge amount of data, but they are very different. The size of the mass data mainly emphasized the amount of data, the characteristics and no special attention. And big data characteristics of transmission rate, volume and the data such as various features are described. Big data processing has general technical architecture. Big data of the 
basic process and traditional data processing procedure of the main difference is that: because of the large data to deal with a great deal of data, unstructured, so in each processing link can be used in parallel processing. Big data analysis and mining is a kind of decision support process, it is mainly based on artificial intelligence, machine learning, pattern recognition, data mining, statistics, database technology, such as highly automated analysis of large data, makes the inductive reasoning, to dig out the potential model, so as to extract useful information in large data. Despite the big data availability theory is not yet mature. But for a particular data engineering problems, can build standardized data format. Due to the purpose of the release data, content, way, time, there is a big difference. Therefore, how to realize the growth of big data availability is big data are the important factors of successful application of the Internet.

In the vast amounts of data in the Internet world, considering the differ in thousands ways of data type, data format, data update, the density of value each have differences, to ensure data availability is a very difficult task. The traditional way is to get high quality for the large data and integration. Include to establish theoretical system of large data availability, namely how to formally said data availability and how to find and fix error data automatically. Internet tax not only is the medium of the Internet trading platform, also carrying the transfer information, promote the role of tax services. Unlike traditional tax, tax Internet platform through face-to-face conversation, customer perception of feelings, found the abnormal behavior of the clients. Therefore, in order to improve the quality of service of the Internet platform of tax, the operation of the customer behavior, usually record the operation of the customer behavior.

\section{The Core Techniques of System}

Development. In recent years, the electronic tax system in our country has got a rapid development and progress, people gradually realized the importance of the electronic tax system which has been widely used in many fields, has obtained the very good achievement. Electronic tax system on information security, however, still exists a lot of loopholes, makes the security of the information data of threat, seriously affected the normal operation of the electronic tax system. Electronic tax system is through the use of taxpayer Internet network or telephone voice platform with the tax authorities for tax information exchange. Taxpayers apply for electronic declare dutiable goods, you can use the computer to fill out and submit the declaration data or using voice platform to submit data reporting. The tax authorities for taxpayers to submit the electronic data of logical audit, comparing with the data of golden tax project at the same time, the right to deal with the results of audit tax returns, and with the relevant Banks to realize real-time exchange of electronic information, implementation withholding tax payment receipt printing, etc.

Business process is: the tax side communication program, in turn, delimit business database retrieval request information, sent to the bank, the bank after receiving written to the buffer database, then dealt with; Bank side middle database for operation, performed a business at a time, the results through the communication program to return to the national side. Duty end interface program writes the result to business database. Implementation and golden tax project, the interaction between the data collection and management software system, from, collection and management software of golden tax project put forward the relevant basic information of the taxpayers, and by using the data of golden tax project check taxpayers, according to the information for checking, the rationality of taxpayer declare information including balance within itself the legitimacy of each table, table, table, such as the balance between to ensure that the declaration data effectively. In the figure one, we use visual flowchart to illustrate the structure of the electronic network system of taxation. 


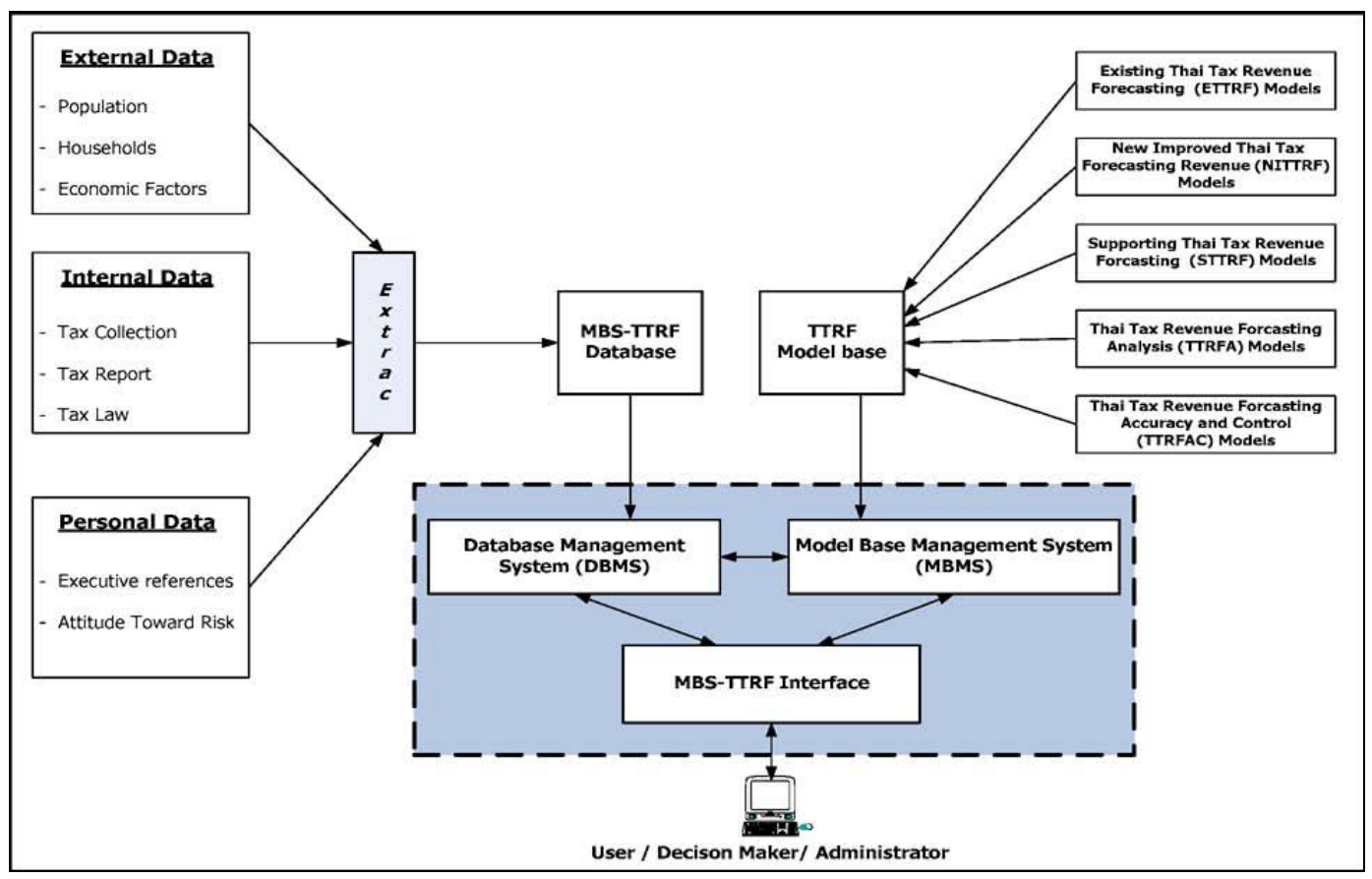

Fig. 2The Organization and Structure of the Electronic Network System of Taxation

The Performance of the Proposed System. Electronic tax evaluation index system is the key of the electronic tax assessment system, its foundation is to assess the nature and characteristics of the object itself, relationships, and movement process, and assessment concept is the basic criterion. Scientific principle which is set index and index system should comply with the assessment of the nature and characteristics of the object itself, relationships, and the movement process. Integrity principle, is the ratio of index system should be complete, and coordination. Maneuverability principle, that is, must fully consider when constructing the index system of evaluating the feasibility of the implementation and the economy. The first is as the support of information systems. Once again is on information system object decision support, last is the performance of the tax. Comparability principle, the general statistical significance is index, the assessment results can be achieved between the object of horizontal comparison and the longitudinal comparison on the time. A complete evaluation system including evaluation purpose, evaluation subject, evaluation object, evaluation ideas, evaluation index, evaluation procedures and methods. In this paper, on the basis of analyzing the characteristics of the tax department of government affairs, clear evaluation purpose, evaluation subject, evaluation object according to the core values of modern government and tax authorities, refining assessment concept, determine the evaluation indexes should follow the principle of design. 


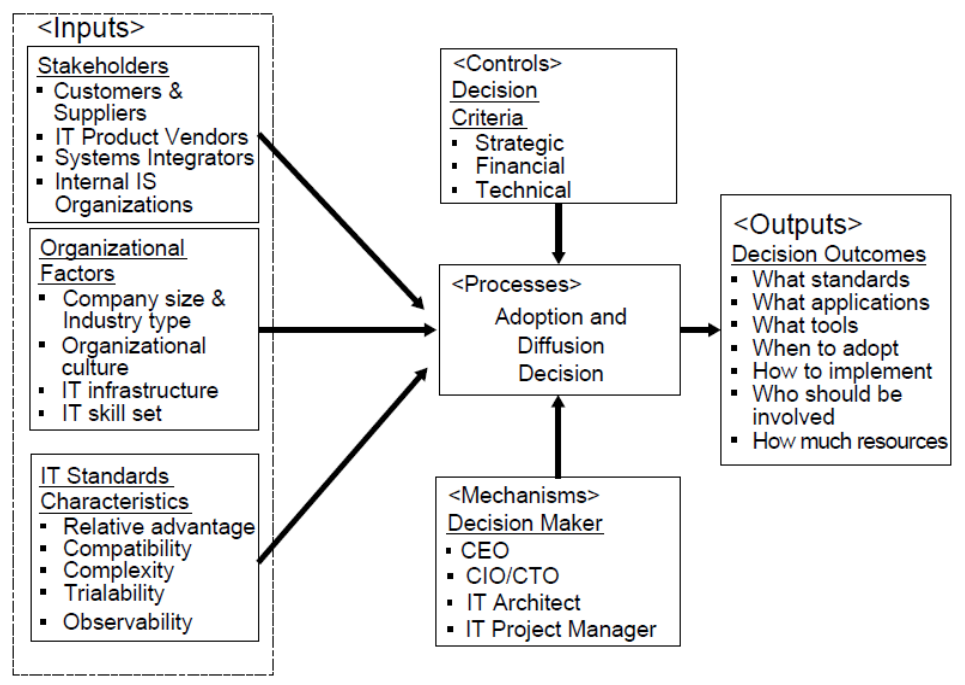

Fig. 3The Standards for Measuring the Performance of the System

\section{Conclusion}

In this paper, we conduct theoretical design and implementation of electronic network system of taxation base on the internet and big data perspective. Tax information in bring people convenient at the same time, its security issues are also of concern. With the development of computer and the network popularization, the important information becomes very easy to get and at the same time cyber-attacks became more and more convenient. Therefore, designing the robust and effective system is urgent and necessary. In the new round of tax reform, there are many urgent needs to solve the major issues, in addition to the necessary theoretical analysis, the major problem is more critical to combine with the actual data analysis. In data analysis, many economic variables are the relationship between people is difficult to use intuition and experience to grasp which must through the data analysis model to find the answer. In the near future, we have scheduled to conduct more research.

\section{References}

[1] Holter H A. Accounting for Cross-Country Differences in Intergenerational Earnings Persistence: The Impact of Taxation and Public Education Expenditure[J]. Social Science Electronic.

[2] Rees R, Rees R. of LaborOptimal Taxation, Child Care and Models of the Household[J]. Social Science Electronic Publishing, 2014.

[3] Dang T V, Morath F. The Taxation of Bilateral Trade with Endogenous Information $[\mathrm{J}]$. Social Science Electronic Publishing,

2015. 